\title{
69. CRACK DISTRIBUTION IN THE UPPER OCEANIC CRUST AND ITS EFFECTS UPON SEISMIC VELOCITY, SEISMIC STRUCTURE, FORMATION PERMEABILITY, AND FLUID CIRCULATION
}

\author{
Douglas M. Johnson, Geophysics Program AK-50, University of Washington, Seattle, Washington
}

\begin{abstract}
The open cracks and filled veins visible in the basalts drilled at DSDP Hole 418A in the North Atlantic have been analyzed and counted for the entire cored section of 546 meters. A discrimination of crack types was developed by counting separately the carbonate-filled, clay-filled, and open (unfilled) cracks, and recounting for crack orientation (horizontal, oblique, and vertical). The crack-depth profiles show several regions of intense fracture, some peaks correlating with lithology change and tectonic activity. The total volume of free interstitial water has been calculated from the primary porosity and open cracks, demonstrating that more water is available from Layer 2 than from the overlying sediments, thus eliminating the need to subduct sediments at the trench to provide fluid for serpentinization and the formation of andesites. From the crack data, bulk fluid permeability of the rock was computed, with an average permeability of $3.9 \times 10^{-4} \mathrm{~cm}^{2}$. The permeability profiles reveal a pattern of thick, highly permeable sequences bounded above and below by less fractured, thin, low-permeable zones, suggesting a model for fluid convection cells in the upper oceanic crust. Cross-correlation of the permeability functions with the downhole geochemistry analyses of the fresh basalts resulted in zero correlation; but, future cross-correlation of the permeability profiles with the geochemical variations in altered materials in the hole may yield important details of the alteration phenomena. The crack data were utilized in conjunction with shipboard physical property measurements to calculate the true bulk density, compressional wave velocity, and total porosity for the entire hole. This revealed a series of layers of high and low velocities, and demonstrated that the laboratory physical property measurements, in concert with the crack-distribution information, can accurately simulate the seismic structure of the oceanic crust. Using the combined physical property data, synthetic seismograms have been computed for Hole 418A, showing that the zones of high crack density are at least one of the causes of sub-basement reflectors in the upper crust.
\end{abstract}

\section{INTRODUCTION}

The effect of internal cracks on the physical properties of earth materials has long been recognized and has received considerable attention in the literature. Changes in seismic velocity, velocity anisotropy, and bulk density, and a strong pressure-dependence of the elastic moduli, have been partly attributed to the crack distribution within the rocks. Although first reported for laboratory samples (Adams and Williamson, 1923; Birch, 1960a, b), the effects ought to be observed also in the field. Fractures in a geologic formation greatly affect its bulk permeability, thus controlling the amount of fluid and any fluid flow patterns within the rock complex. They also influence, to a degree, heat flow and any geochemical alteration that may occur in the formation.

This paper gives the results of an analysis of crack distribution observed in cores drilled from 110-m.y.-old oceanic crust in the North Atlantic (DSDP Hole 418A). The hole was singularly important in that a near-record 546 meters of basalt was drilled, with high average core recovery
(72 per cent). The primary data base consists of a series of profiles of eight different crack parameters, each with a sampling interval of 1.5 meters or less. Crack anisotropies, volumes, and bulk permeabilities are calculated from these data, providing a rather unique body of information that will have a significant bearing on the geophysical investigation of the oceanic crust. Finally, by combining the shipboard physical property data with the crack data, composites of the effective bulk density and compressional wave velocity profiles for the hole are computed. These corrected profiles allow, for the first time, a quantitative link between laboratory physical property measurements and seismic experiments in the field; synthetic seismograms are computed to demonstrate that the observed zones of high cracking density will be manifested as sub-basement reflectors in marine seismic profiles.

\section{TECHNIQUE AND EXPERIMENTAL ERROR}

The cracks visible in each core section were counted according to their classified type. The crack groupings were 
distinguished in terms of orientation and material filling, with type separations for horizontal $\left(90^{\circ} \pm 10^{\circ}\right)$, vertical $\left(0^{\circ}\right.$ $\left.\pm 10^{\circ}\right)$, and oblique $\left(45^{\circ} \pm 35^{\circ}\right)$ cracks, and then for unfilled (open), calcium carbonate-filled and clay (smectite)-filled cracks. The dominant orientation or filling material was used in classifying each crack. Average crack width and the estimated amounts of breccia and smectite in each section were additional parameters recorded. The core sections typically varied from 0.5 to 1.5 meters in length, with one to seven sections in a core, depending upon core recovery, which averaged 72 per cent. The individual parameters were summed for each section, hence the sampling interval is 1.5 meters or less for each parameter.

Fractures caused by the drilling operations may bias the crack totals in some core sections; however, after detailed examination of the open cracks it was concluded that drilling did not significantly affect the crack distributions. Bias is possible in the observations due to the vertical drilling angle of the bit and to the angular restrictions of the crack criterion. It is not entirely clear that weighting factors should be applied to the crack data to compensate for these problems; hence, the information included in this report has not been filtered, weighted, or processed in any way. A dominance of oblique cracks over horizontal and vertical cracks is a natural outcome of the wider angular acceptance band of the oblique criterion, but it will not affect comparisons of the relative changes between the oriented cracks, and, of course, has absolutely no effect upon the filled crack observations.

The report includes only the information derived from the recovered rock. Since 28 per cent of the core was not recovered, the bulk formation properties reported here can be considered as minimum values. The material composing the 28 per cent loss could be either sediments, flow breccias, or densely cracked massive basalts, and it would ill serve the purpose of this paper to make conjectures about the missing material. Arbitrary corrections, therefore, have not been made to the average formation properties, and discussions are based only on the direct observations of the core.

Errors in the analysis occur primarily in the counting of cracks. Improper counting technique and counter's fatigue are the major error-producing elements. To minimize error, counting was done under constant lighting conditions during two 2-hour periods of the day (mid-morning and midafternoon). An error estimate is difficult to make owing to the nature of the work. Counting errors are considerable in the absolute sense: recounting at random depths has discovered miscounts as high as 60 per cent. Generally, the error can be kept to 10 per cent, with a marked increase in the statistic for sections with a high cracking density. The sum of all the oriented cracks must be equal to the sum of all the filled-type cracks for a given core section. Thus an estimate of error that is at least internally self-consistent can be made by noting the difference between the sums of oriented and filled cracks for each core section, which then constitutes the relative counting error. This is superior to simply taking a second count using the same criteria (just orientation or filling), since the method is different for each count. Figure 1 is a profile of counting error with depth, the percentage error being based upon the sum of all the crack types for each section, and the calculated difference between the two

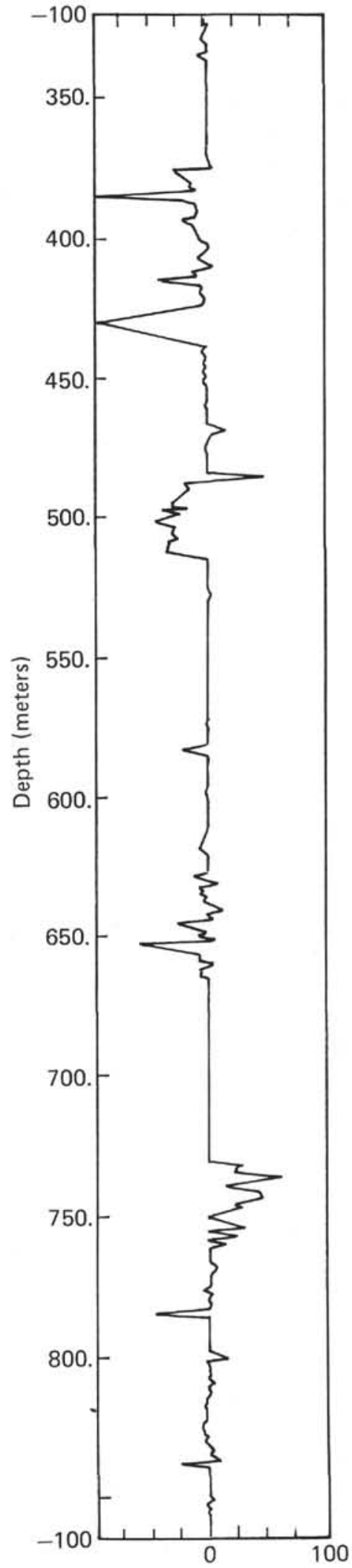

Figure 1. Relative error profile for the Hole $418 \mathrm{~A}$ crack count. Error was determined as described in text. Error increases dramatically in brecciated zones. Average absolute error is estimated to be 10 per cent, based on recounting at random depth locations in the cores. 
crack groups. The errors do not correlate with any of the parameters measured, and appear to be random. The sections with large errors were recounted for the analysis reported in this paper.

\section{CRACK FEATURES}

A detailed description of the structural characteristics of the cracks observed in the cores is clearly impossible. However, generalized description of the average crack features can be made and is relevant to efforts at modeling the physical characteristics of cracked solids and the crust in general. A composite of the most common crack features is given in Figure 2.

The cracks, in a very gross sense, were the shape of thin tapered disks, having an aspect ratio (length/width) of well over 50 . They are not large, their maximum length measuring $620 \mathrm{~mm}$ for a vertical crack (Core 81, Section 3) and their maximum thickness $50 \mathrm{~mm}$ (Core 73, Section 6). The average length of the vertical cracks is $150 \mathrm{~mm}$, their average width $2 \mathrm{~mm}$. An estimate of the average crack length is not easy to make, because of the geometric restrictions of the drill hole; it is reasonable to assume, however, that the character of a horizontal crack is the same as that of a vertical one. Since the average horizontal and oblique widths are of the same order of magnitude as the vertical cracks, a maximum horizontal or oblique crack length of less than 10 meters appears to be a reasonable assumption. Crack widths eventually decrease to hairline fractures at the extremities of the cracks. Secondary crack growth is commonly observed normal to or at acute angles to the main crack. The walls of the cracks are smooth but not continu-

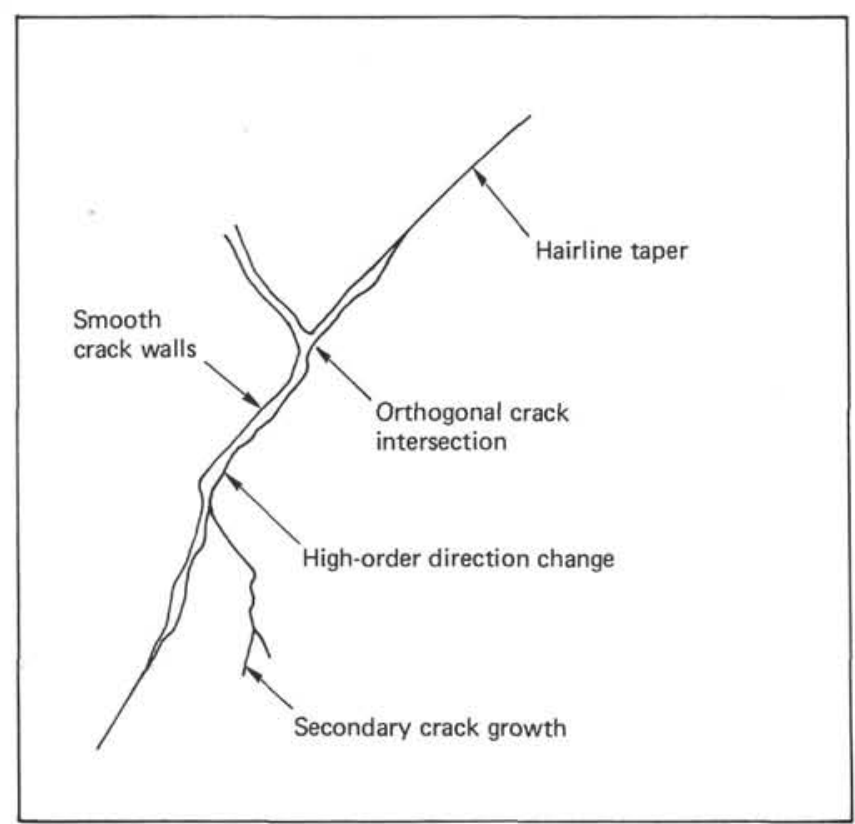

Figure 2. Composite diagram of typical crack features observed in the cores. Crack walls are smooth but are marked by changes in direction of the crack, producing an angular, ragged appearance. Secondary crack growth was common. Termination of the crack is not abrupt but rather is a taper, narrowing down to hairline dimensions. ous, as the short crack paths change direction rapidly in an angular, sometimes orthogonal, fashion, although the large-scale path trajectory is relatively constant (Figure 2).

The spatial relationships among the cracks are generally random, although two types of spatial geometries are seen throughout the core at irregular, non-systematic positions. The first commonly found feature is a pattern of parallel or subparallel cracks occurring in a relatively small area (about $0.25 \mathrm{~m}^{2}$ or less) and almost always in a horizontal orientation and typically filled with calcium carbonate. These cracks are thin, $10 \mathrm{~mm}$ or less, and range in number from three to six or more. Although the mechanisms of this apparent swarming is not known, the cracks are parallel to the ocean surface and hence normal to the geothermal gradient; this implies a thermal mechanism, with crack formation occurring immediately after extrusion. In addition, these cracks form zones of weakness in shear along the horizontal plane. A careful check of the cores revealed that many of the clean horizontal cracks previously attributed solely to drilling are in fact breaks along these planes of weakness. The second crack geometry is that of orthogonal crack intersections (Figure 2), which may also be related to thermal fracturing. The orthogonal intersections are quite common and occur in every lithologic unit; in some instances they bridge horizontally oriented parallel cracks. This bridging is a clue to the origins of the orthogonally intersecting fractures, since a secondary fracture system will occur normal to the first set of thermal cracks in a cooling body (Jaeger and Cook, 1969; Price, 1966; Johnson, 1970). This, however, does not eliminate the possibility that the orthogonal cracks were formed as a result of a simple change in the principal stress axes, which is a common feature in stressed materials after an initial failure (Price, 1966; Badgley, 1965). In the case of cracks normal to the thermal gradient, fluid injection into the primary crack (parallel to the gradient) could rotate the local thermal gradient by $90^{\circ}$ by cooling off the crack surface, thus allowing secondary fracture perpendicular to the original fracture but parallel to the local gradient.

A final point concerning crack widths must be made in connection with the pressure release due to removal of the core to the surface. The calculated effective pressure at hole bottom is $0.11 \mathrm{kbar}$, equivalent to a burial depth of about 350 meters in dry continental material. Expansion of the core due to pressure release will be negligible since the static compressibility of igneous rocks is about $2 \times 10^{-6}$ bar (Brace, 1965), and hence the core would expand by 0.16 per cent in the radial direction. Core expansion would also be evidenced by tension faults in the wider smectite- and carbonate-filled cracks, but this has not been observed. It is important to emphasize, therefore, that crack widths observed accurately represent the widths as they existed at depth.

\section{CRACK DISTRIBUTION}

The crack-distribution profiles in Figure 3 are the basic results of the counting analysis. Eight profiles are shown, one each for the six crack types, plus one for summed vertical and oblique cracks, and one for total cracks. The profiles have the appearance of a reflection seismogram, with spikes of high cracking density occurring at irregular intervals in the hole. Generally in these areas of numerous 


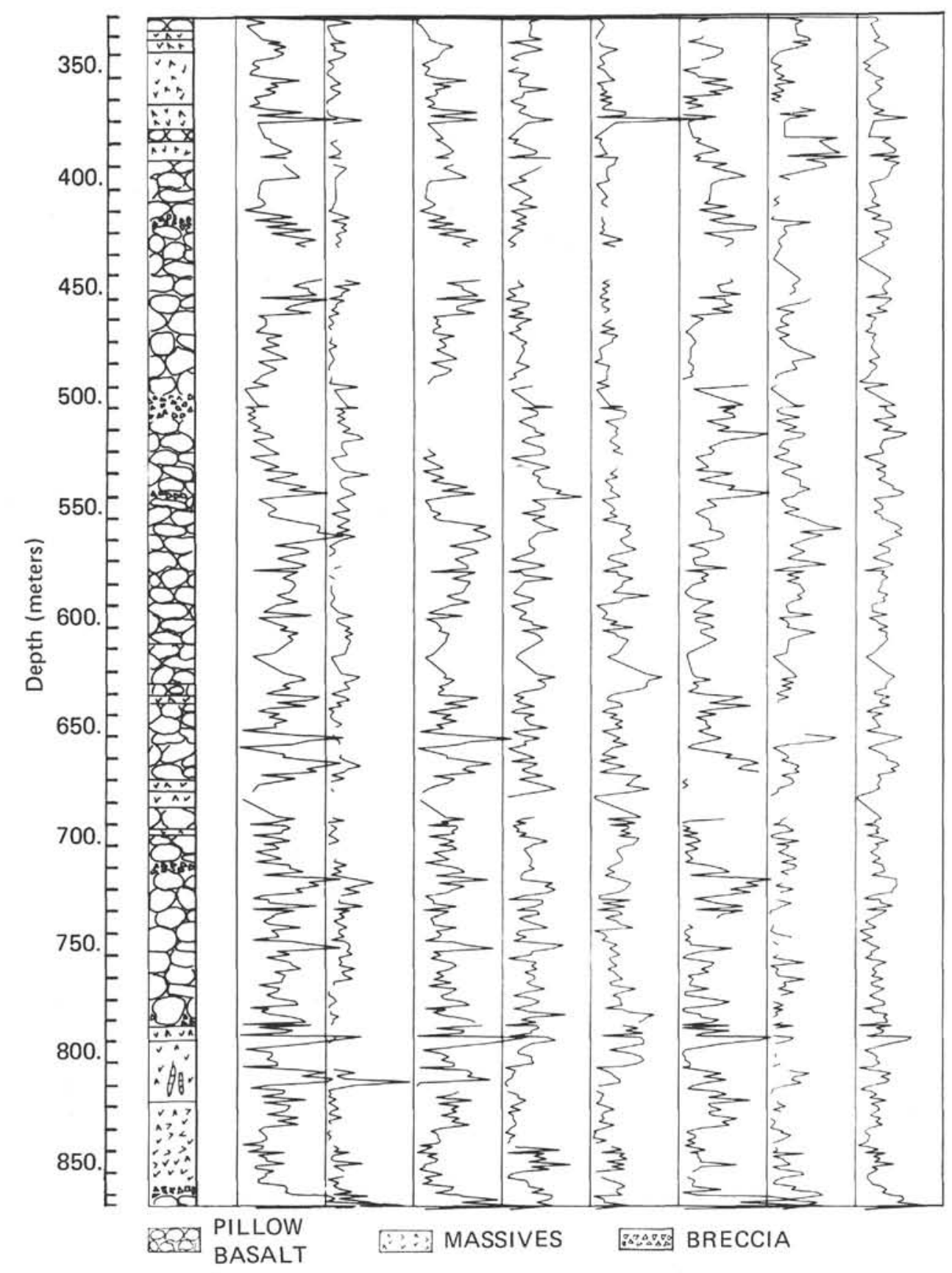

Figure 3. Crack distributions observed in the cores drilled at Hole 418A. The profiles represent, from left to right, (a) vertical + oblique cracks, (b) vertical, (c) oblique, (d) horizontal, (e) unfilled (open) cracks, (f) smectite-filled, ( $g$ ) carbonate-filled, and (h) total (open + smectite + carbonate) cracks. The scale is 33 cracks per division for all profiles except for total cracks, which has a scale of 100 cracks per division. The lithology log on the left is for comparison. Gaps in the plotted profiles represent zero core recovery.

cracks, there was an increase in all crack types indicative of the randomness of the cracking phenomena. The data density is quite high and almost every spike or trough has significance. There are several regions of intense fracturing in the profiles, notably at (360-370), (780-805), and a large zone of brecciation at (498-505), but the small cracking events at (380-390) and (855-866) are also significant in that they represent changes in lithology as can be seen in Figure
4. The figure further demonstrates that brecciation and smectite content are not strictly limited to the zones of lithology change, but also pinpoint locations of geologic activity occurring within lithologic units after cooling.

\section{CRACK ANISOTROPY AND VOLUMES}

The crack distribution profiles have been divided arbitrarily into 10 regions of equal length, and relative crack 
anisotropies and crack volumes for each region have been calculated and are presented in Tables 1 and 2 . The anisotropy of the oriented cracks is determined by summing each crack type for the region and then computing the ratios of vertical to horizontal, vertical to oblique, and oblique to horizontal cracks. The volumes were calculated by assuming that all cracks extended the width of the core, and crack geometries were rectangular for the vertical cracks, ellipsoidal and at $45^{\circ}$ to the horizontal for oblique cracks, and circular disks for the horizontal cracks. Filled cracks were considered as oblique cracks for the volume calculations. These computations indicate there is a general predominance of oblique cracks through the formation, followed by horizontal and then vertical cracks. These results do not take into account core recovery which may be controlled to a certain degree by the presence of vertical cracks; hence the possibility exists that the vertical-crack data are an underestimate of the true distribution. The filled-crack volumes show the surprising feature of dominance of smectite over carbonate and unfilled cracks. This is attributed to the overwhelming presence of smectite in large cracks and in all breccias (Figure 4). Horizontal, unfilled cracks, as mentioned above, are clearly a consequence of drilling effects upon horizontal carbonate veins, but do not represent a majority of either horizontal or unfilled cracks. The carbonate-crack volumes are statistically the most reliable of the filled types, because they can be easily spotted. The

TABLE 1

Crack Volumes for Each Crack Type for 10 Equally Spaced Regions in Hole 418A (values in $\mathrm{cm}^{3}$ )

\begin{tabular}{ccccr}
\hline Region & Depth $(\mathrm{m})$ & Carbonate & Smectite & Unfilled \\
\hline 1 & 374.6 & 13132 & 15974 & 11995 \\
2 & 429.2 & 15405 & 21033 & 7901 \\
3 & 483.8 & 13132 & 15633 & 8527 \\
4 & 538.4 & 12790 & 26377 & 13302 \\
5 & 593.0 & 20294 & 16997 & 18418 \\
6 & 647.6 & 11142 & 17566 & 19669 \\
7 & 702.2 & 15235 & 16372 & 23251 \\
8 & 756.8 & 8186 & 23364 & 17509 \\
9 & 811.4 & 11312 & 20181 & 28253 \\
10 & 866.0 & 15690 & 29163 & 15462 \\
\hline
\end{tabular}

Note: Hole radius is $8 \mathrm{~cm}$; each "region" has a total volume of $271,433 \mathrm{~cm}^{3}$.

TABLE 2

Crack Anisotropy for Three Orientations for 10 Equally Spaced Regions in Hole 418A

\begin{tabular}{ccccc}
\hline Region & Depth $(\mathrm{m})$ & $\mathrm{v}: \mathrm{h}$ & $\mathrm{v}: \mathrm{o}$ & $\mathrm{o}: \mathrm{h}$ \\
\hline 1 & 374.6 & 0.4310 & 0.4296 & 1.0034 \\
2 & 429.2 & 0.5959 & 0.3952 & 1.5078 \\
3 & 483.8 & 0.5636 & 0.2379 & 2.3697 \\
4 & 538.4 & 0.6077 & 1.5725 & 0.3864 \\
5 & 593.0 & 0.3401 & 0.2326 & 1.4622 \\
6 & 647.6 & 0.5828 & 0.5289 & 1.1019 \\
7 & 702.2 & 0.3820 & 0.2589 & 1.4752 \\
8 & 756.8 & 0.6119 & 0.5885 & 1.0398 \\
9 & 811.4 & 0.4061 & 0.2597 & 1.5635 \\
10 & 866.0 & 0.4973 & 0.3753 & 1.3253 \\
\hline
\end{tabular}

Note: $\mathrm{v}=$ vertical $; \mathrm{o}=$ oblique $\mathrm{h}=$ horizontal. total volume of the carbonate cracks is $136,318 \mathrm{~cm}^{3}$ for the hole, or 4.98 per cent of the total volume drilled.

The secondary porosity which is due to the cracks has an appreciable effect upon the total volume of water subducted with the crust into a trench system. The total volume of the unfilled cracks in the 546 -meter hole is $164,287 \mathrm{~cm}^{3}$, corresponding to a porosity of 6 per cent. Since the crack profiles show no indication of decreasing crack density, we may possibly project this 6 per cent porosity to a depth of at least $2 \mathrm{~km}$, if not to the base of the crust. At $2 \mathrm{~km}$ the total volume of unfilled cracks would be $601,750 \mathrm{~cm}^{3}$. This can be compared to a 300-meter sediment layer of 50 per cent porosity, which would have a water volume of $753,982 \mathrm{~cm}^{3}$ for the hole. This does not take into account the water available in the interstitial pore spaces (primary porosity), nor that available in the smectite- and carbonate-filled cracks. This information has direct implication for the question of a water source in the subduction zone. Assuming that the values obtained in this experiment are typical of oceanic crust, then it is clear that a greater amount of water is being subducted into the trench by Layer 2 than by sedimentary Layer 1. It is, in fact, not necessary to require the structurally difficult task of subduction into the trench of sedimentary materials to obtain the high water volumes required for serpentinization and the formation of andesites.

Figure 5 is a plot of the crack ratios from Table 2. The observational restrictions of the core does not allow azimuthal orientation of the cracks; hence a fabric description can be made only with respect to the dip of the fractures. General predominance of a particular crack orientation in a depth region may affect the velocity and attenuation of seismic waves traveling at that depth (Christensen, 1972). Figure 5 demonstrates that there are regions of high-crack anisotropy occurring within the depths drilled into Layer 2. The vertical-to-horizontal $(\mathrm{v}-\mathrm{h})$ ratio for the 10 regions reveals little in terms of anisotropy, with a relatively constant ratio of $0.50 \pm 0.10$ for the entire length of the hole. A certain degree of oscillation can be seen in the $\mathrm{v}$-h plot, but this is not a dominant feature. The constancy of the $\mathrm{v}$-h ratio is the principal reason for the apparent mirror images observed with the oblique-to-horizontal (o-h) and vertical-tooblique $(\mathrm{v}-\mathrm{o})$ ratios in Figure 5 . Both plots reveal drastic changes in the anisotropies at depths between 400 and 550 meters, and then strong fluctuations in an oscillatory manner similar to the $\mathrm{v}$-h plot for the rest of the hole. The major ratio change begins as a steep increase in oblique cracks, which peaks in region 3 (430 to $484 \mathrm{~m}$ ). Region 4 is characterized by an extremely large drop in the number of oblique cracks, with a reduction of the o-h ratio from 2.37 in region 3 to 0.38 in region 4 . The cause of this sudden drop is not known. Although the largest brecciated unit in the hole does occur in this zone, and another appears lower in the section - suggesting a possible rotation mechanism - this in itself cannot totally explain the phenomena. That is because an increase in vertical or horizontal cracks would also be expected, yet the v-h ratio is constant. This anisotropy jump also is in phase with the deeper and smaller ratio changes, producing the above-mentioned cyclic pattern with depth. This overall pattern may be a result of rotation of major blocks at the ridge crest, or it could represent local orientation variations in the geothermal gradient. To provide a 


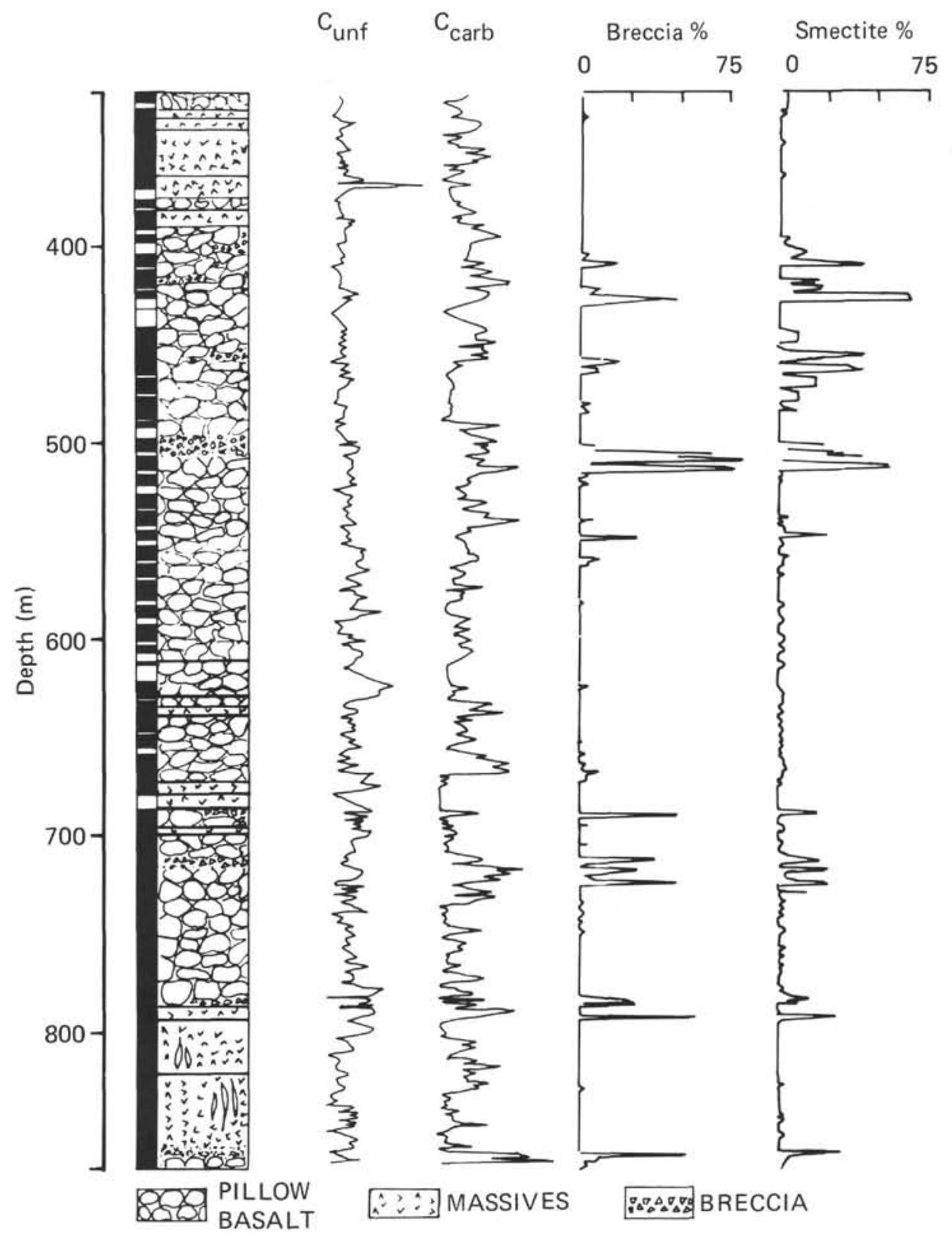

Figure 4. Core lithology; the distribution of carbonate-filled $\left(C_{\text {arb }}\right)$ and unfilled cracks ( $\left.C_{u n f}\right)$, and estimated percentages of breccia and smectite. Breccia and smectite generally correspond to changes of lithological units and with flow breccias within the pillow basalts. The crack profiles have some correlation with lithology change, but also show a wide variation in crack density throughout the section. The column to the left of the lithology log is a core recovery log, where the black represents core recovered, white represents core loss.

reasonable solution, however, further study is needed. The latter includes details of the petrology and paleomagnetism with depth in the hole.

\section{CRUSTAL PERMEABILITY}

The bulk of permeability of a geologic formation is a measure of the fluid conductivity of the complex. The permeability of an igneous rock, in a homogeneous unfractured condition, is typically very low, on the order of $10^{-15}$ to $10^{-17} \mathrm{~cm}^{2}\left(1\right.$ darcy $\left.=10^{-8} \mathrm{~cm}^{2}\right)($ Brace, 1977; Johnson,
1977). The presence of a single crack penetrating the rock will have a tremendous effect upon increasing the permeability of the material (Nelson and Handin, 1977), and in a rock formation the permeability due to fractures can be the controlling element for fluid flow. The crack-distribution data of this study can be used to calculate the bulk permeability of the entire 546-meter section of basalts, providing a unique viewpoint from which to consider geochemical alteration, fluid convection, and seismic properties of the upper oceanic crust. 


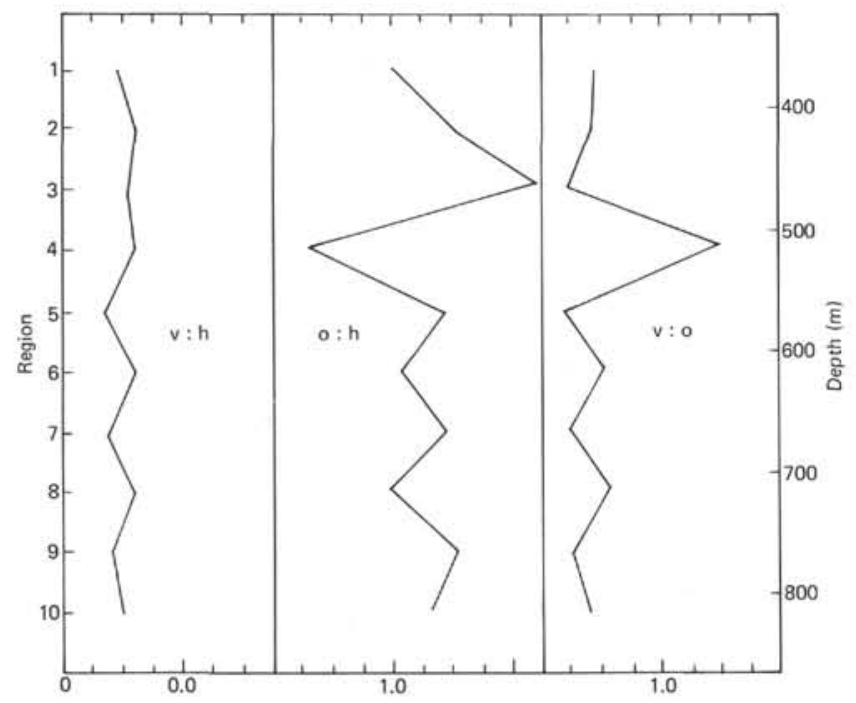

Figure 5. Crack anisotropy computed from crack-distribution data. Vertical to horizontal $(v: h)$ ratio is constant relative to the oblique to horizontal $(o: h)$ and vertical to oblique (v:o) ratios. the $o: h$ and v:o are almost mirror images of each other, indicative of the stable $v: h$ ratio. Strong changes in crack orientation are evident in regions 2,3 , and 4 .

The bulk permeability was calculated from the crack data, using the formulation of Lister (1974); this is similar to the formulations used by other workers (Nelson and Handin, 1977; Parsons, 1966). A permeability value, K, for each core section was computed from the formula

$$
\mathrm{K}=\frac{\mathrm{W}^{3}}{12 \times \mathrm{Y}}
$$

where $\mathrm{W}$ is the effective crack width and $\mathrm{Y}$ the crack spacing. The permeabilities for the filled cracks were calculated by ignoring the effects of the filling materials; hence, the carbonate- and smectite-crack permeabilities represent, in essence, the paleopermeabilities of the crustal section and not the present-day permeability. The result of the computations is a series of eight profiles, one for each single type of crack and two for the combined data, just as for the crack profiles.

The computed permeability-depth profiles (Figure 6) show that the upper crust is definitely not homogeneous in terms of fluid conduction. Primary in importance is the extremely high permeabilities occurring throughout the rock complex, with values averaging about $10^{-4} \mathrm{~cm}^{2}$ for the open-crack permeabilities. These values can be compared with the permeabilities of hydrothermal wells $\left(\sim 1 \times 10^{-i}\right.$ $\mathrm{cm}^{2}$, Elder, 1965) or with the intrinsic permeabilities of the unfractured basalts, which range around $10^{-15} \mathrm{~cm}^{2}$ (Johnson, this volume). The effect of this contrast is that in zones of high cracking density a very high fluid conductivity exists, but percolation of fluid is reduced drastically in regions of low cracking density where the permeability decreases and approaches that of the solid basalts. The permeability profiles show several large peaks corresponding in part to breaks in lithology, brecciated units, and pillow basalts as well as to simple increases in cracking. At 500 meters there is a region of very high permeability occurring in a large brecciated zone; the permeability here is orders of magnitude greater than that of the surrounding rock. This zone will act as a major fluid conduit, particularly if it extends laterally a moderate distance. Other interesting features are the two zones of lower permeabilities at 370 to 470 meters and 600 to 630 meters; these will act as flow barriers relative to the highly conductive zones. Several other zones of exceptionally high permeability are found at 328 to 335 meters, 360 to 370 meters, 630 to 700 meters, and 856 to 866 meters.

The permeability profiles may be used to gain an estimate of the initial permeability at the ridge crest and also to infer the change in permeability with time, as the cracks filled with carbonates and clays. The permeability due to all the cracks, as shown in Figure 6, has an average value of $10^{-4}$ $\mathrm{cm}^{2}$, with peaks as high as $1.59 \times 10^{-2}$.

These high permeabilities indicate that after each new period of igneous activity at the ridge, the material was cooled and then fractured extensively forming most of the cracks observed in the core and allowing a very high volume of sea water to flush through the fractured complex. Casual observation of many carbonate-filled cracks reveals that the crack walls are coated with smectite and hence predate the carbonate infilling. A model with the basalts cooling, cracking and then being flushed through with sea water, with subsequent precipitation of smectites and then calcium carbonate, implies that the permeability profiles of Figure 6 represent (at any given depth) the sequence of permeability change at each stage of alteration, from post cooling/ fracture to smectite filling and then carbonate filling. With each stage, the bulk permeability on the average drops about one-half an order of magnitude; thus, the effects of filling some cracks does not alter the order of magnitude of the permeabilities and will not drastically hamper fluid flow.

The permeability profiles, when viewed as a whole, appear as a series of alternating zones of high and low permeability, suggesting a pattern of fluid movement which would occur within the highly permeable zones and be bounded by the low-permeable zones. The formation of fluid convection cells within these zones can be proved only by numerical calculation and will be the subject of future work. The assumption that convection exists within these layers is not simplistic nor obvious as the layers are relatively thin, the fluid will have multiple components in solution, and the thermal gradient will be decreasing with distance from the ridge, all of which complicate the criteria for convection. The convection pattern, if it exists, could appear as in Figure 7, with several cells of variable dimension occurring within the section. Alternatively, the convection cells may be in the form of a single layer encompassing the entire section and possibly Layer 2 . The model shown does not consider the effect of the layer of sediments above the basalts. The permeability of the sediment cover will be much lower than the bulk permeability of the basalts, since the permeabilities of pelagic sediments are typically about $10^{-11}$ to $10^{-13} \mathrm{~cm}^{2}$ (Pearson and Lister, 1972; Robertson, 1967). The effect of the sediment cover will be to control the percolation rate of sea water into the basalts of Layer 2, 


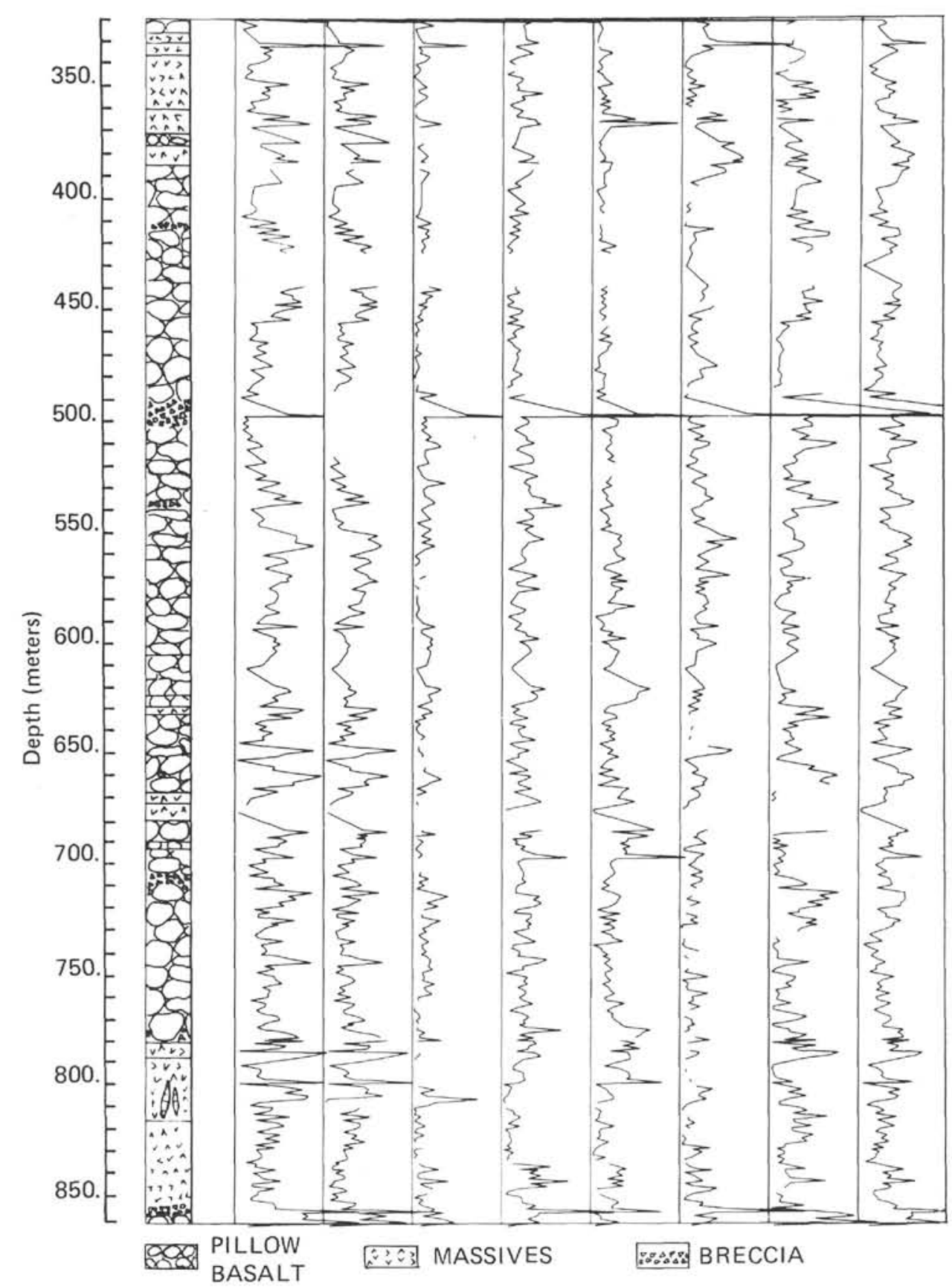

Figure 6. Permeability profiles computed from the crack-distribution data of Hole 418A.

The profiles represent variations in fluid conduction caused by (from left to right) (a) vertical + oblique cracks; (b) vertical; (c) oblique; (d) horizontal; (e) unfilled (open) cracks; the cracks filled by $(f)$ smectites; $(g)$ carbonates; and the total contribution of unfilled, smectite and carbonate-filled cracks (h). A scaling factor of 500 has been applied to all the permeability values except for total permeability, which has a factor of 250. Each vertical division line represents a permeability of $2 \times 10^{-3} \mathrm{~cm}^{2}$ $\left(4 \times 10^{-3}\right.$ for total permeability). Note that permeabilities less than $10^{-4}$ will fall on the baseline. Lithology log is for comparison. The spike in permeability at 500 meters has been clipped to fit the plot; the greatest permeability attained was $1.59 \mathrm{X}$ $10^{-2} \mathrm{~cm}^{2}$.

and to be the controlling element in any convection involving the sediment layer.

The shipboard chemical analyses of pillow basalts suggest systematic changes in the percentage amounts of
$\mathrm{K}_{2} \mathrm{O}$, $\mathrm{MgO}$, and $\mathrm{CaO}$, and consequently to contact with sea water, with proximity to the pillow margins. The present study of crack distributions and bulk permeabilities has shown strong fluctuations in bulk permeability throughout 

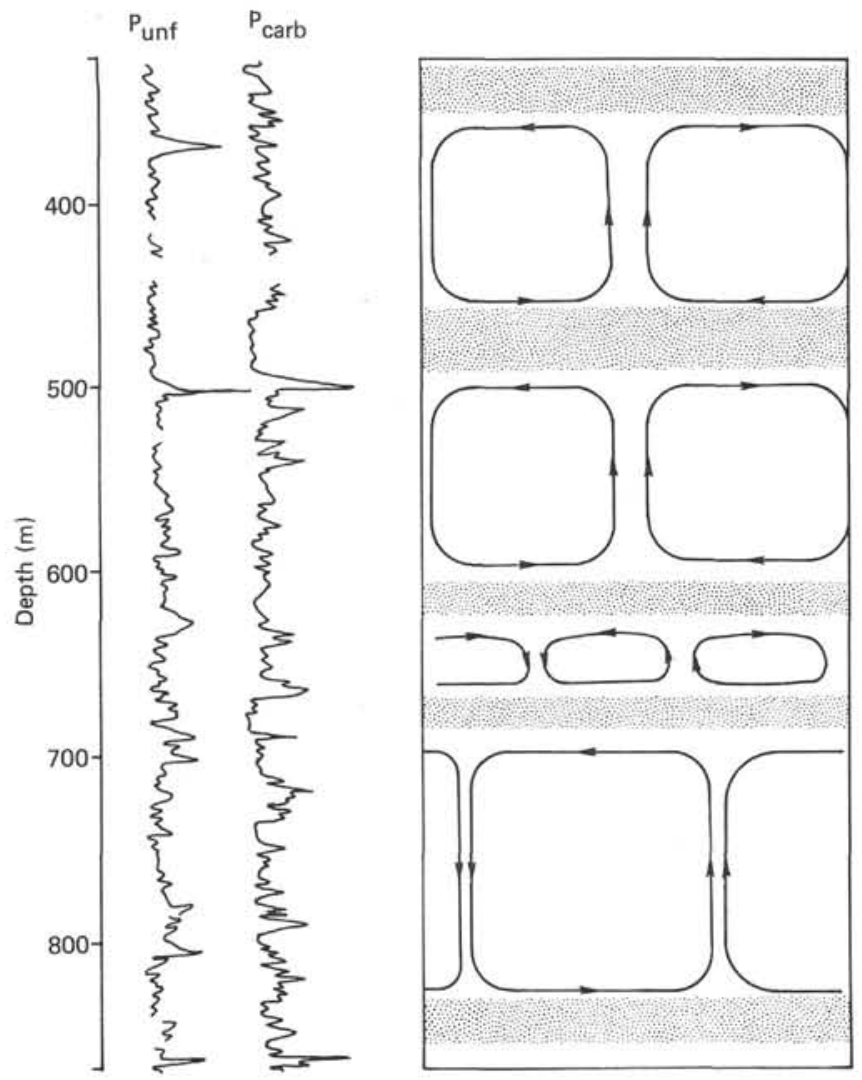

Figure 7. Possible hydrothermal convection scheme for Layer 2, as inferred from the permeability profiles for Hole $418 \mathrm{~A}$. Fluid flow will be effectively stopped by regions of low crack density, such as massive units. Shaded areas are regions of lower permeability and hence potential flow barriers. $P_{\text {unf }}$ and $P_{\text {carb }}$ are the profiles of unfilled crack permeability and carbonate crack permeability. These convection cells may be nested within a much larger cell which could encompass all of Layer 2. This is particularly valid if there is a minimal lateral extent of the massive units.

the depth of the drill hole. If, as a result of these cracks, a high degree of fluid circulation exists in the upper crust there may be some functional relationship between downhole permeability and variations in basalt geochemistry with depth. If circulation has existed continually in the pattern suggested by the permeability profiles, then the degree of chemical alteration will reflect the pattern. Any linear dependence of chemistry upon permeability for the entire hole can be detected by numerical cross-correlation of the two data sets. Consequently, a computer program was developed that would interpolate the geochemistry data by a simple integration technique and then cross-correlate each oxide profile with every permeability profile. The computations were also made with the shipboard physical property data. The cross-correlation consists of computing

$$
C_{k}=w \sum_{j}^{i=c_{0}} P_{j} G_{j-k} K=0, \ldots m
$$

where $C_{k}$ is the cross-correlation, $P_{j}$ is the digitized permeability, $\mathrm{G}_{j-k}$ is the geochemical profile, and $\mathrm{W}$ is a normalizing weighting function. The process may be visualized as shifting the two digitized functions past each other in space and summing the products of each digitized interval. The permeabilities and X-ray fluorescence (XRF) data from the shipboard studies were numerically interpolated and then resampled at equally spaced intervals to minimize computational errors in the cross-correlation. Zero correlation indicates a lack of pervasive alteration in the sampled basalts, which in the case of Hole $418 \mathrm{~A}$ has been clearly demonstrated by more direct means (see Hole Summaries, Volume 1). All parameters measured in the XRF analyses and all physical property measurements were crosscorrelated with each of the eight permeability profiles, resulting in the computation of 88 cross-correlation functions. Typical of these functions are those for total permeability, carbonate-crack permeability and unfilled-crack permeability as shown in Figure 8. No significant correlation exists for these nor for any of the other permeability functions. A serious problem in the analysis is the poor sample density of the XRF data, which causes statistical aliasing of the higher frequency variations in the data set and thus limits the accuracy of the cross correlations.

An additional series of computations is needed, using geochemistry profiles, which has been developed from a dense sampling of alteration materials in the core. Crosscorrelation, or possibly a cross-association analysis of the $\mathrm{XRF}$ data with segments of the permeability data, may reveal functional relationships within lithologic units that have not been detected by the present analysis.

\section{SEISMIC STRUCTURE}

The bulk density and compressional wave velocity profiles of the hole will be significantly affected by the variations in crack density and type, and thus must be corrected by taking into account the densities and velocities of the materials filling the cracks. The bulk density was recomputed using the crack volumes, the relative abundances of solid basalt and of the three types of filled cracks, and the measured densities of the basalts, sea water, smectite, and calcium carbonate from the hole. Velocity was computed in the same manner, but with the measured compressional wave velocities of the materials. The corrected physical property profiles are shown in Figure 9, which also includes total, primary, and secondary porosity profiles. The primary porosity is the interstitial pore space; secondary porosity is that due to the cracks, and total porosity is the combination of the two. The pressure effects of depth were taken into account only for the velocity computations, since there will be almost no volume change resulting from the $0.11 \mathrm{kbar}$ hole-bottom pressure as mentioned earlier. The effect of this pressure upon seismic velocity is significant and was compensated for by assuming a linear effective pressure gradient in the hole ( 1 to 110 bars from the top of hole to bottom) and a velocity/pressure gradient of $0.13 \mathrm{~km} / \mathrm{s} / \mathrm{kbar}$ measured from the sampled basalts.

The recomputed physical property data resolve in part a major inconsistency between field and laboratory seismic measurements. Typical laboratory values of compressional wave velocities for oceanic basalts range from $5.5 \mathrm{~km} / \mathrm{s}$ and 


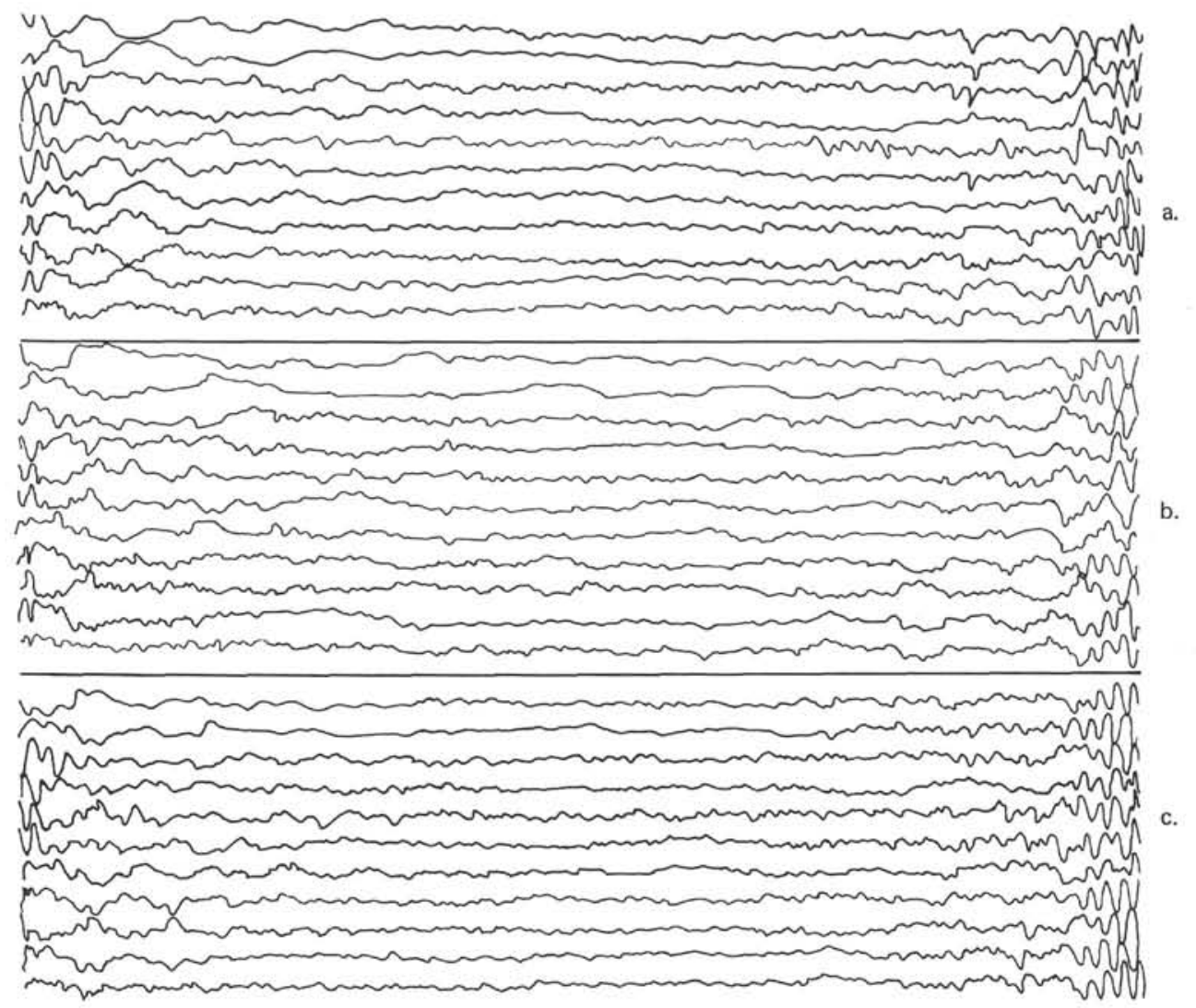

Figure 8. Cross-correlation of (a) unfilled-, (b) carbonate-, and (c) total-crack permeability profiles with XRF oxide analyses and physical property measurements for Hole $418 \mathrm{~A}$. The parameters cross-correlated with each permeability are, from top to bottom in each box, $\mathrm{Al}_{2} \mathrm{O}_{3}, \mathrm{Fe}_{2} \mathrm{O}_{3}, \mathrm{MgO}, \mathrm{CaO}, \mathrm{K}_{2} \mathrm{O}, \mathrm{TiO}, \mathrm{Fe} / \mathrm{Mg}$, grain density, bulk density, primary porosity, and compressional velocity. The computations show no correlations between permeability and fresh basalt chemistry for the hole when considered as a complete unit. More detailed analyses of alteration materials may show permeability-chemistry correlations within individual lithologic units.

above at room pressures (Christensen and Shaw, 1970), contrasting significantly with refraction experiments indicating an average Layer 2 velocity of $5.0 \pm 0.6 \mathrm{~km} / \mathrm{s}$ (Ludwig et al., 1971; Raitt, 1963) and with some regions with (upper) Layer 2 velocities of $4.0 \mathrm{~km} / \mathrm{s}$ or less (Talwani et al., 1971; Le Pichon et al., 1965). Great contrasts in velocities within Layer 2 indicate distinct materials within the layer such as sediments interlayered within the basalts, but differences in velocities as great as 40 per cent have been found in this study to be a direct result of increased crack density. Thus, the velocity discrepancies between laboratory and field measurements are not the result of measuring the wrong materials or measuring them in the wrong physical environment, but are due rather to the large-scale cracking in Layer 2. Regions of Layer 2 where crack density is low will have p-wave velocities comparable with the laboratory measurements, and steady decreases in veolcity will be observed with higher crack densities.

The recomputed velocity and density profiles shown in Figure 9 can be modeled as a series of layers of constant velocity and density. This layering effect suggests that the major cracking zones in the upper crust may be observed as seismic reflectors in marine seismic profiles. The lateral extent of large-cracking zones is not expected to be great, perhaps 200 or 300 meters at maximum. The zone thickness must be at least a quarter wavelength of the principal impinging wavelet to act as a reflector, although a series of several thin layers may also combine for the same effect. The resulting phenomena on a seismic profile would then be that of several sub-basement reflectors appearing at various depths, each reflector being of low-to-moderate intensity (due to low-density contrasts in the layers) and only a few hundred meters in length. Since at the time of this writing a deep penetration, high-resolution marine seismic profile is not available for the Hole 418A area, prediction of subbasement reflectors is a moot point. A synthetic reflection seismogram can be computed, however, to demonstrate that the layering effect is a valid basis upon which to make the prediction. We utilized the reflectivity method of Fuchs (1968, 1971), as modified by Fuchs and Müller (1971), in the computation. The profile is equivalent to that of a seismic system where the hydrophone streamer trails the sound source by 200 meters with a streamer length of 500 meters. The synthetic seismogram computed from the physical property data and crack distributions is shown in Figure 10. This reveals that the zones of high-cracking density and the 


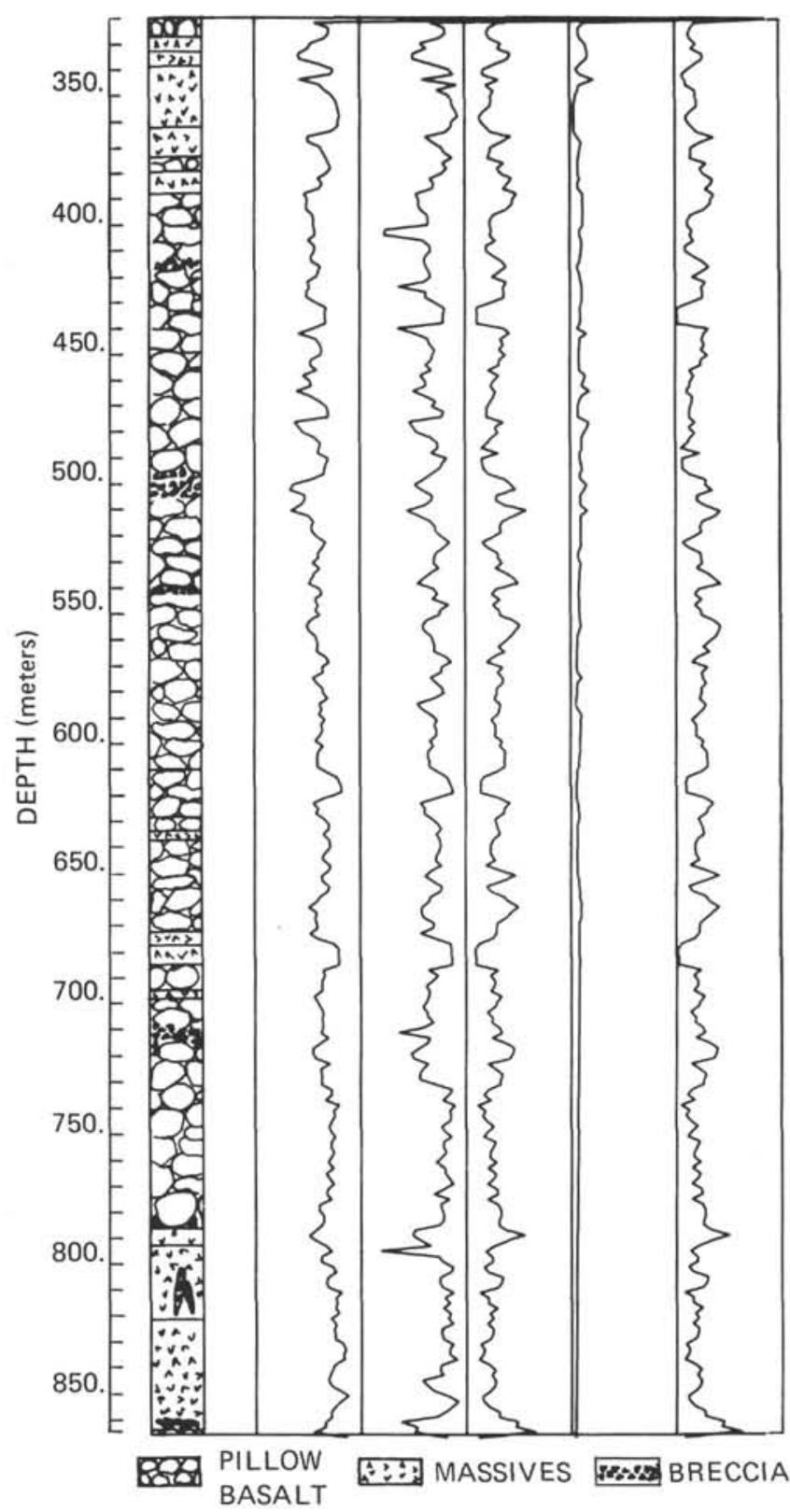

Figure 9. Recomputed physical property profiles, generated by combining the crack data with shipboard physical property measurements of the basalts, smectites and carbonates found in the cores drilled at Hole 418A. The lithology log is for comparison. The profiles and scales are: (a) density, 2.0 to 3.0; (b) compressional wave velocity, 3.0 to $6.0 ;(c)$ total porosity; 0.0 to 67 per cent; (d) primary porosity, 0.0 to 67 per cent; (e) secondary (crack) porosity, 0.0 to 67 per cent. Significant changes in the density and velocity profiles result after incorporation of the effects.

general variation in crack distribution are indeed manifested as sub-basement reflectors.

\section{SUMMARY}

The crack distribution in 110-m.y.-old oceanic crust in the north Atlantic has been determined by direct observation of cores. Eight different parameters have been used in classifying the cracks, and this discrimination permits a number of important observations to be made concerning the physical nature of Layer 2. This data base, in conjunction with shipboard physical property data, was used to carry out a series of geophysical calculations that provide a dramatically improved quantitative picture of the upper oceanic crust. The following are the major findings of this study:

1) Zones of high-cracking density exist in Layer 2 with an open-crack average of $0.07 \mathrm{cracks} / \mathrm{cm}^{2}$, average crack length of $150 \mathrm{~mm}$, crack width of $2 \mathrm{~mm}$ and aspect ratio of 50 or greater.

2) These zones are regions of extremely high permeability (open-crack average of $3.9 \times 10^{-4} \mathrm{~cm}^{2}$ ) and thus act as major fluid conduits within Layer 2.

3) Large volumes of free water exist within the interstitial pore spaces and cracks, potentially providing more water for subduction than Layer 1 sediments.

4) Thin-layer convection cells are a strong possibility within Layer 2, but for the Layer 1 to Layer 2 region, the sediments of Layer 1 with bulk permeabilities seven to nine orders of magnitude smaller than Layer 2 act as the controlling element to convection and percolation.

5) Cross-correlation of the permeability function with the downhole geochemistry profiles of the fresh basalts showed zero correlation. It is proposed that the technique be applied to the geochemical analyses of the altered materials in the hole as soon as complete analyses are available.

6) These cracking zones alter the bulk physical properties of Layer 2, causing decreases in velocity by as much as 40 per cent and bulk density by 20 per cent, and explain in part the discrepancy between laboratory and field seismic data.

7) The effects upon physical properties are strong enough that major cracking zones can appear as seismic reflectors, and this may in fact be the origin of subbasement reflectors in Layer 2 .

\section{ACKNOWLEDGMENTS}

The author has benefited from conversations with Anton Hales, Gary Latham, Mark Landisman, and James Carter. A. Hales, J. Carter, and C.R.B. Lister reviewed the manuscript. Hubert Staudigel and Matt Salisbury were very helpful with their encouragement during the initial phase of this work, and I thank them. Joe Gettrust and Walt Mooney were of tremendous help with the synthetic seismogram computation. The synthetics were computed at the Hawaii Institute of Geophysics. This research was supported in part by the Office of Naval Research Contract N-00014-75-C0502 for the University of Washington and in part through the Programs in Geosciences, The University of Texas at Dallas.

\section{REFERENCES}

Adams, L. H. and Williamson, E. D., 1923. The compressibility of minerals and rocks at high pressures, J. Franklin Inst., v. 195 , p. 475.

Badgley, P. C., 1965. Structural and tectonic principles: New York (Harper and Row).

Birch, F., 1960a. The velocity of compressional waves in rocks to 10 kb, Part 1, J. Goephys Res., v. 65, p. 1083.

$1960 \mathrm{~b}$. The velocity of compressional waves in rocks to $10 \mathrm{~kb}$, Part 2, J. Geophys. Res., v. 65, p. 1103.

Brace, W.F., 1965. some measurements of linear compressibility of rocks, J. Geophys. Res., v. 70, p. 391. 


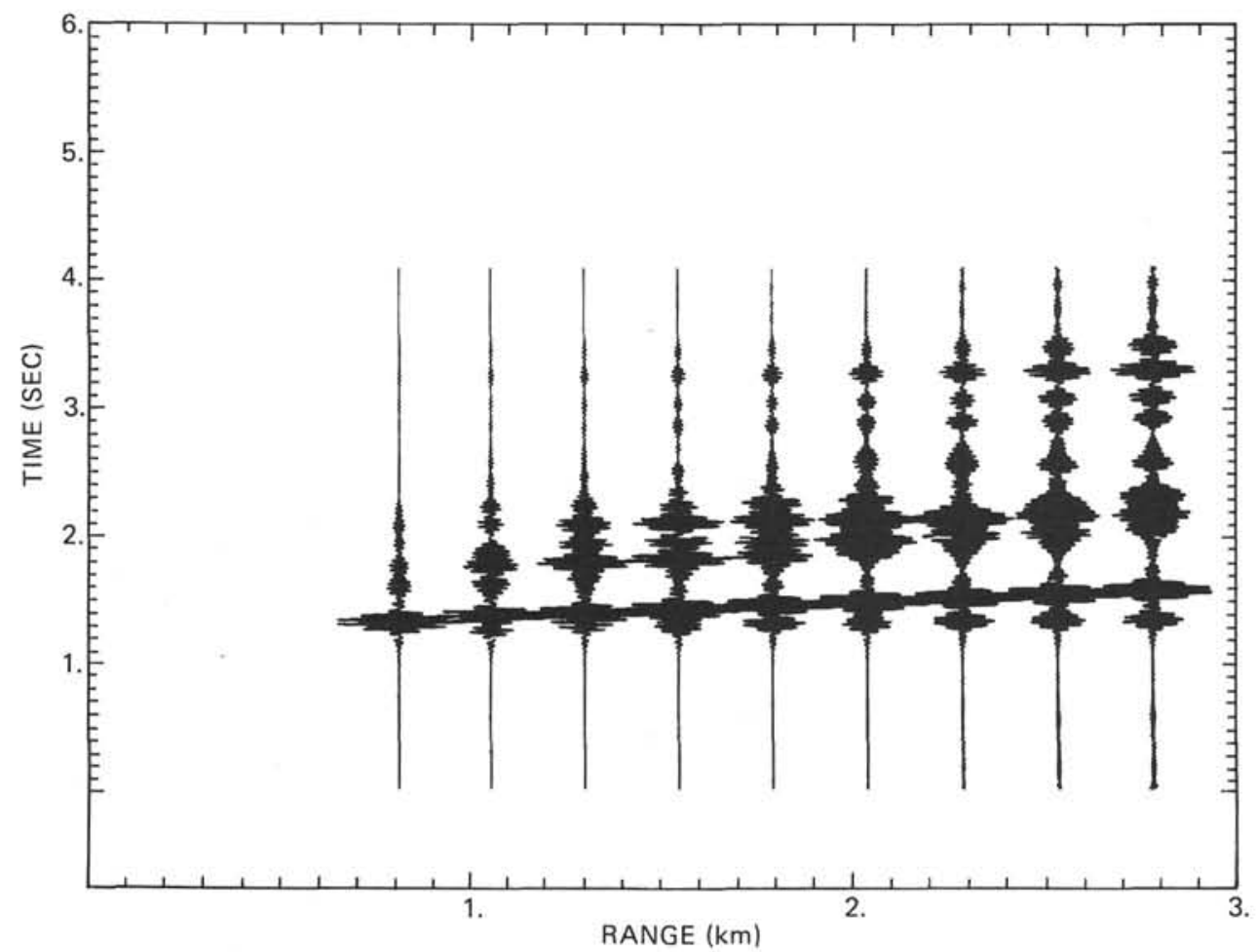

Figure 10. Synthetic seismogram computed from physical property data and crack distributions (see Figure 9). Major cracking zones are predicted to be seismic reflectors. Energy source frequency $30 \mathrm{~Hz} \pm 10 \mathrm{~Hz}$.

, 1977. Permeability from resistivity and pore shape, $J$. Geophys. Res., v. 82, p. 3343.

Christensen, N., 1972. Seismic anisotropy in the lower oceanic crust, Nature, v. 237 , p. 450.

Christensen, N. and Shaw, G. H., 1970. Elasticity of mafic rocks from the Mid-Atlantic Ridge, Geophys. J. Roy. Astron. Soc., v. 20 , p. 271 .

Elder, J. W., 1965. Physical processes in geothermal areas, Am. Geophys. Union. Mono., v. 8, p. 211.

Fuchs, K., 1968. The reflection of spherical waves from transition zones with arbitrary depth-dependent elastic moduli and density, J. Phys. Earth, v. 16, p. 27.

, 1971. The method of stationary phase applied to the reflection of spherical waves from transition zones with arbitrary depth-dependent elastic moduli and density, Z. Geophys., v. 37, p. 89 .

Fuchs, K. and Müller, G., 1971. Computation of synthetic seismograms with the reflectivity method and comparison with observations, Geophys. J. Roy. Astron. Soc., v. 23, p. 417.

Jaeger, J. C. and Cook, N. G. W., 1969. Fundamentals of rock mechanics: London (Methuen).

Johnson, A., 1970. Physical processes in geology: San Francisco (Freeman, Cooper).

Johnson, D. M., 1977. Crack distribution and character in layer 2 basalts (abstract), EOS. Trans. AGU, v. 58, p. 1174.
Le Pichon, X., Houtz, R. E., Drake, C. L., and Nafe, J. E., 1965. Crustal structure of the mid-ocean ridges, 1: seismic refraction measurements, J. Geophys. Res., v. 70, p. 319.

Lister, C. R. B., 1974. On the penetration of water into hot rock, Geophys. J. Roy. Astron. Soc., v. 39, p. 465.

Ludwig, W.J., Nafe, J. E., and Drake, C. L., 1971. Seismic refraction. In Maxwell, A. E. (Ed.), The sea: New York (Interscience), v. 4 (1), p. 53-84

Nelson, R. and Handin, J., 1977. Experimental study of fracture permeability in porous rock, Am. Assoc. Petrol. Geol. Bull., v. 61 , p. 227.

Parsons, R. W., 1966. Permeability of idealized fractured rock, Soc. Petrol. Engr. J., p. 126-136.

Pearson, W. C. and Lister, C. R. B., 1973. Permeability measurements on a deep-sea core, J. Geophys. Res., v. 78, p. 7786.

Price, N. J., 1966. Fault and joint development in brittle and semi-brittle rock: New York (Pergamon).

Raitt, R. W., 1963. The crustal rocks. In Hill, M. (Ed.), The sea: New York (Interscience), v. 3, p. 85-102.

Robertson, E. C., 1967. Laboratory consolidation of carbonate sediment. In Richards, A. (Ed.), Marine geotechnique: Urbana (Univ. Illinois Press).

Talwani, M., Windisch, C. C., and Langseth, M. G., Jr., 1971. Reykjanes ridge crest; a detailed geophysical study, $J$. Geophys. Res., v. 76, p. 473. 